\title{
Humeral avulsion of the glenohumeral ligament of the shoulder
}

\author{
R V P de Villiers (MB ChB, MMed (Rad D)) \\ J F de Beer (MB ChB, MMed (Orthop)) \\ $\mathrm{K}$ van Rooyen (MB ChB) \\ P E Huijsmans (MD) ${ }^{2}$ \\ C P Roberts (FRCS (Trauma and Orthop) \\ D F du Toit (D Phil (Oxon), PhD, MB ChB, FCS (SA), FRCS (Ed), FICA (USA)) ${ }^{3}$ \\ ${ }^{1}$ Dr van Wageningen and Partners, Vergelegen and Stellenbosch Mediclinics \\ ${ }^{2}$ Cape Shoulder Institute, Cape Town \\ ${ }^{3}$ Department of Anatomy, Stellenbosch University, W Cape
}

\section{Background}

A 24-year-old rugby player presented to an orthopaedic surgeon with a history of dislocation of the left shoulder. It reduced spontaneously and dislocated again later during the same match.

On examination there was no residual instability, but the apprehension test for anterior instability was positive. Speed $s$ test as well as O Brien s test for SLAP (Superior Labrum Anterior to Posterior tear) lesions were negative. There were no signs of rotator cuff tear or impingement.

\section{Case report and diagnostic procedures}

The patient was sent for an X-ray series consisting of the routine impingement series and additional views of the inferior glenoid (Bernageau and Westpoint). No fracture of the inferior glenoid was demonstrated.

A magnetic resonance imaging (MRI) scan was then requested to evaluate the labro-capsular structures and to exclude an occult fracture or articular surface tear of the rotator cuff. The MRI scan showed an avulsion on the inferior glenohumeral ligament attachment to the humerus (Figs 1 and 2). This is described as a HAGL lesion (Humeral Avulsion of the Glenohumeral Ligament). ${ }^{1}$

Arthroscopy of the shoulder confirmed the diagnosis of a HAGL lesion (Fig. 3). An open procedure was performed to repair the lesion. The postoperative period was uncomplicated and the patient made a full recovery with full range of motion and no residual instability.

\section{CORRESPONDENCE:}

R V P de Villiers

PO Box 317

Somerset West

7129

Tel: 021-851 5545

Fax: 021-852 2697

E-mail: rmldev@mweb.co.za

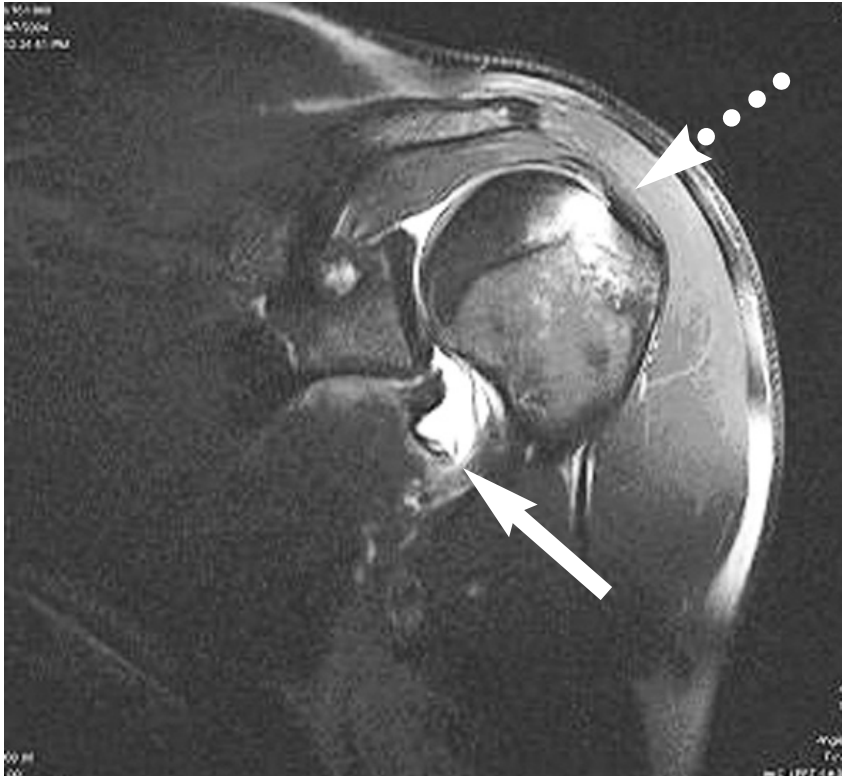

Fig. 1. MR arthrogram of the shoulder. Coronal T1 fat-saturated study shows avulsion of the inferior glenohumeral ligament from the attachment onto the humerus (arrow). Note the J-shaped configuration of the axillary recess, which is normally $U$-shaped. Note the impaction fracture of the posterolateral humeral head (dotted arrow).

\section{Discussion}

The HAGL lesion is an uncommon cause of recurrent dislocation of the shoulder ${ }^{1,10,13}$ although biomechanical studies have found a higher percentage of HAGL lesions. ${ }^{2}$ Because of the anterolateral to inferolateral location, HAGL lesions can be difficult to visualise during arthroscopy and a preoperative diagnosis using MR arthrography can be useful. The most common consequence of a shoulder dislocation in the young subject is a Bankart lesion or a Bankart variant of the anterior glenolabral complex. ${ }^{5-7,10,11}$

In HAGL lesions there is a macroscopic tear of the capsule at the humeral attachment, also described as a reversed Bankart lesion. Associated injuries are common and include rotator cuff tears, Hill-Sachs fracture of the postero-superior humeral head, biceps tendon lesions and brachial plexus injury. . 4, $12^{2}$ 


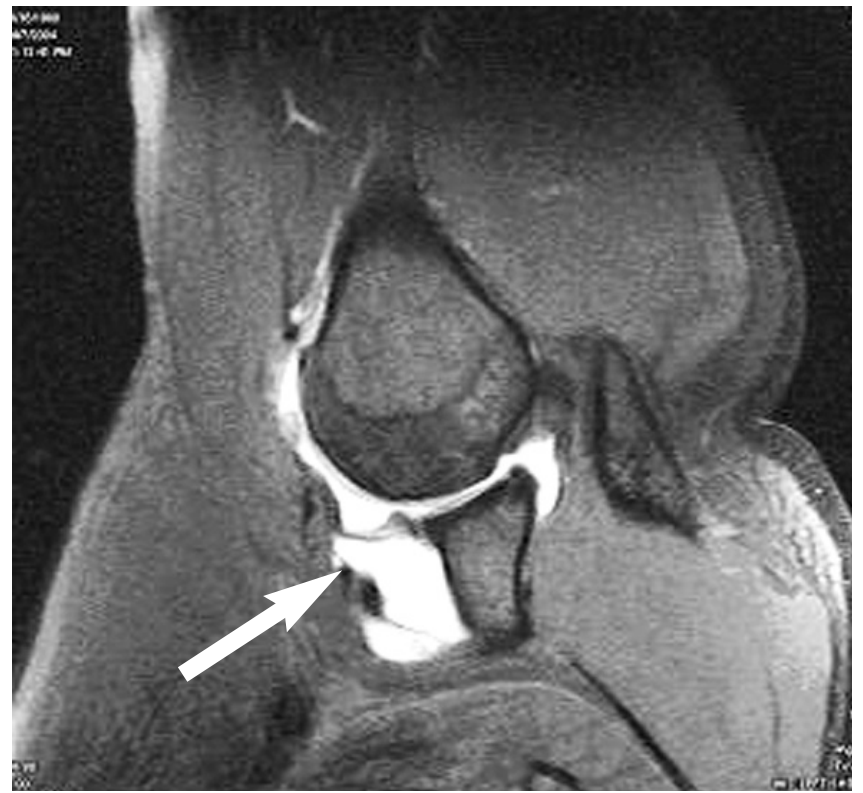

Fig. 2. MR arthrogram of the shoulder. ABER (abduction external rotation) view shows a lax inferior glenohumeral ligament.

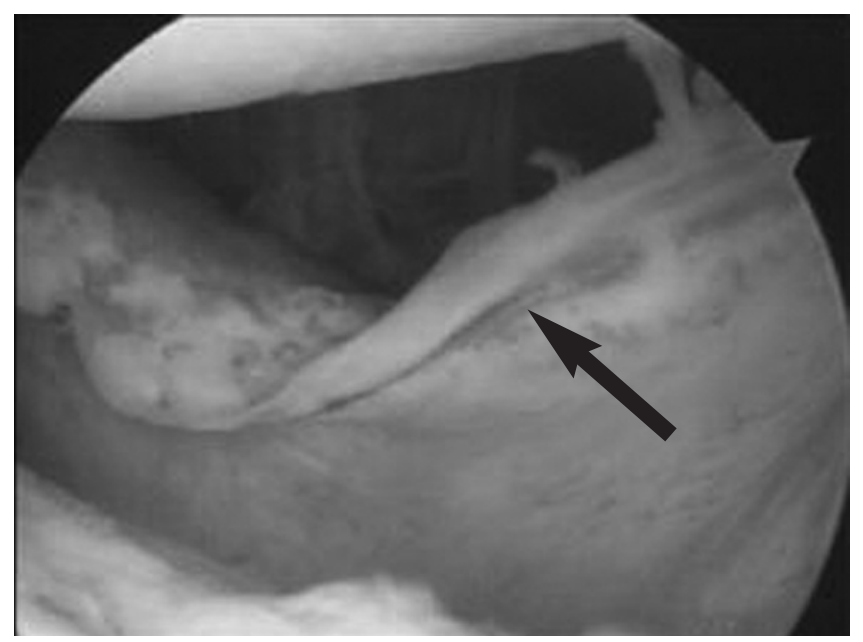

Fig. 3. Arthroscopic view, looking from posterior through the joint at the anterior capsule. The capsule is torn off the humerus, with the fibres of the subscapularis seen deep to it.
Imaging with MR arthrography is the non-invasive investigation of choice.4, 8, 9 Management is usually surgical, although conservative management is used in selective cases.

\section{References}

1. Bach BR, Warren RF, Fronek J. Disruption of the lateral capsule of the shoulder. A cause of recurrent dislocation. J Bone Joint Surg $\mathrm{Br}$ 1988;70:274-6.

2. Bigliani LU, Pollock RG, Soslowsky LJ, Flatow EL, Pawluk RJ, Mow VC. Tensile properties of the inferior glenohumeral ligament. J Orthop Res 1992; 10:187-97.

3. Bui-Mansfield LT, Taylor DC, Uhorchak JM, Tenuta JJ. Humeral avulsions of the glenohumeral ligament: imaging features and a review of the literature. Am J Roentgenol 2002;179:649-55.

4. Coates MH, Breidahl W. Humeral avulsion of the anterior band of the inferior glenohumeral ligament with associated subscapularis bony avulsion in skeletally immature patients. Skeletal Radiol 2001;30:661-6.

5. Habermeyer P, Gleyze P, Rickert M. Evolution of lesions of the labrum-ligament complex in posttraumatic anterior shoulder instability: a prospective study. J Shoulder Elbow Surg 1999;8:66-74.

6. Hintermann B, Gachter A. Arthroscopic findings after shoulder dislocation. Am J Sports Med 1995;23:545-51.

7. Palmer WE, Caslowitz PL. Anterior shoulder instability: diagnostic criteria determined from prospective analysis of $121 \mathrm{MR}$ arthrograms. Radiology 1995; 197:819-25.

8. Sanders TG, Morrison WB, Miller MD. Imaging techniques for the evaluation of glenohumeral instability. Am J Sports Med 2000;28:414-34.

9. Stoller DW. MR arthrography of the glenohumeral joint. Radiol Clin North Am 1997;35(1):197-116.

10. Taylor DC, Arciero RA. Pathologic changes associated with shoulder dislocations. Arthroscopic and physical examination findings in first-time, traumatic anterior dislocations. Am J Sports Med 1997;25:306-11.

11. Wall MS, O Brien SJ. Arthroscopic evaluation of the unstable shoulder. Clin Sports Med 1995;14:817-39.

12. Warner JJ, Beim GM. Combined Bankart and HAGL lesion associated with anterior shoulder instability. Arthroscopy 1997;13:749-52.

13. Wolf EM, Cheng JC, Dickson K. Humeral avulsion of glenohumeral ligaments as a cause of anterior shoulder instability. Arthroscopy 1995:11:600-7. 